SVN

Neurology

\section{Identifying sex-specific differences in the carotid revascularisation literature: findings from a scoping review}

To cite: Yogendrakumar $\mathrm{V}$, Shamy M, Dewar B, et al. Identifying sex-specific differences in the carotid revascularisation literature: findings from a scoping review. Stroke \& Vascular Neurology 2021;0. doi:10.1136/svn-2020000744

- Additional material is published online only. To view please visit the journal online (http://dx.doi.org/10.1136/svn2020-000744).

Received 9 November 2020 Revised 9 December 2020 Accepted 2 January 2021
D) Check for updates

(c) Author(s) (or their employer(s)) 2021. Re-use permitted under CC BY-NC. No commercial re-use. See rights and permissions. Published by BMJ.

For numbered affiliations see end of article.

Correspondence to

Dr Michel Shamy;

mshamy@toh.ca

\section{ABSTRACT}

Objective No systematic review of the literature has dedicated itself to looking at the management of symptomatic carotid stenosis in female patients. In this scoping review, we aimed to identify all randomised controlled trials (RCTs) that reported sex-specific outcomes for patients who underwent carotid revascularisation, and determine whether sufficient information is reported within these studies to assess short-term and long-term outcomes in female patients.

Design, setting and participants We systematically searched Medline, Embase, Pubmed and Cochrane libraries for RCTs published between 1991 and 2020 that included female patients and compared either endarterectomy with stenting, or any revascularisation (endarterectomy or stenting) with medical therapy in patients with symptomatic high-grade (>50\%) carotid stenosis. Results From 1537 references examined, 27 eligible studies were identified. Sex-specific outcomes were reported in 13 studies. Baseline patient characteristics of enrolled female patients were reported in 2 of those 13 studies. Common outcomes reported included stroke and death, however, there was significant heterogeneity in the reporting of both periprocedural and long-term outcomes. Sex-specific differences relating to the degree of stenosis and time from index event to treatment are largely limited to studies comparing endarterectomy to medical therapy. Adverse events were not reported by sex.

Conclusions Only half of the previously published RCTs and systematic reviews report sex-specific outcomes.

Detailed analyses on the results of carotid artery intervention for female patients with symptomatic stenosis are limited.

\section{INTRODUCTION}

Carotid revascularisation can benefit select patients with symptomatic carotid stenosis. However, there is debate within the community regarding the degree of benefit observed in female patients. ${ }^{12}$ Interpretation of extant trial data is challenging, as the trials were not designed to study sex differences, and it is unknown whether observed differences reflect true biological differences or relate to study sampling. ${ }^{3-5}$ In addition, while interaction terms have been non-significant in many of the major trials, there has been, in general, an under-representation of female patients within carotid stenosis trials. A failure to see an interaction effect may therefore reflect inadequate statistical power. ${ }^{6}$ This has led to the proposal of novel randomised controlled trials (RCTs) of carotid revascularisation versus best medical therapy (BMT) in women only. ${ }^{2}$ These RCTs would randomise female patients away from standard-of-care interventions and would need to have a strong scientific foundation to be ethically justifiable.

While prior systematic reviews have looked at sex-based differences in carotid stenosis management, they have focused on carotid endarterectomy (CEA) in asymptomatic and symptomatic patients, or included nonrandomised data, resulting in heterogenous findings. No systematic review has yet addressed the optimal management (CEA, carotid stenting (CAS) or BMT) of female patients with recently symptomatic highgrade carotid stenosis.

The goal of this scoping review is to determine whether the benefit of carotid revascularisation in female patients can be reliably assessed using existing RCT data, and whether there are sufficient data on outcomes to assess the need for future trials.

\section{METHODS}

The authors declare that all supporting data and methodological detail are available within the article and online-only supplement. The protocol for this study was previously published, ${ }^{7}$ and this study complies with the Preferred Reporting Items for Systematic Reviews and Meta-Analyses extension statement for scoping reviews. ${ }^{8}$ As a scoping review, our aim was to identify publications of RCTs or related material (systematic reviews, meta-analyses) that reported sexspecific data in relation to the management 
Table 1 List of studies with sex-specific outcomes

\begin{tabular}{|c|c|c|c|c|}
\hline Study & Female/male & Interventions & Per cent stenosis & Outcome(s) assessed \\
\hline $\mathrm{ECST}^{11}$ & $850 / 2168$ & CEA/BMT & $0 \%-99 \%$ & $\begin{array}{l}\text { Model of stroke-free life expectancy } \\
\text { stratified by age and per cent stenosis }\end{array}$ \\
\hline SPACE $^{1314}$ & $338 / 858$ & CEA/CAS & $>50 \%$ & $\begin{array}{l}\text { 30-day risk of death of any cause, } \\
\text { ipsilateral stroke or haemorrhage } \\
30 \text {-day risk of stroke and death and } 2- \\
\text { year risk of ipsilateral ischaemic stroke } \\
\text { (combined) }\end{array}$ \\
\hline EVA-3S ${ }^{15}$ & $130 / 397$ & CEA/CAS & $>60 \%$ & $\begin{array}{l}\text { 30-day risk of death, any stroke and 4- } \\
\text { year risk of ipsilateral stroke (combined) }\end{array}$ \\
\hline CAVATAS $^{16}$ & $152 / 352$ & CEA/CAS & $>60 \%$ & $\begin{array}{l}\text { 8-year risk of any stroke or perioperative } \\
\text { death (combined) }\end{array}$ \\
\hline \multicolumn{5}{|c|}{ Pooled individual patient data meta-analysis } \\
\hline $\begin{array}{l}\text { NASCET and } \\
\mathrm{ESCT}^{45}\end{array}$ & $1718 / 4175$ & CEA/BMT & $>50 \%$ & $\begin{array}{l}\text { 5-year relative risk of ipsilateral } \\
\text { ischaemic stroke or death, stratified } \\
\text { by time from last symptomatic event } \\
\text { to randomisation } \\
\text { 5-year risk of stroke and death in } \\
\text { surgery patients, stratified by per } \\
\text { cent stenosis and time from last } \\
\text { symptomatic event to randomisation } \\
5 \text {-year risk of ipsilateral ischaemic } \\
\text { stroke and any stroke or death within } \\
30 \text { days of randomisation (combined) } \\
5 \text {-year risk of ipsilateral ischaemic } \\
\text { stroke and any stroke or death within } \\
30 \text { days of randomisation (combined), } \\
\text { stratified by per cent stenosis }\end{array}$ \\
\hline $\begin{array}{l}\text { EVA-3S, SPACE, } \\
\text { ICSS, CREST trials }^{9}\end{array}$ & $1437 / 3317$ & CEA/CAS & Multiple thresholds & $\begin{array}{l}\text { 120-day risk of any stroke or death } \\
\text { and 5-year risk of ipsilateral stroke } \\
\text { (combined) } \\
\text { 5-year risk of ipsilateral stroke }\end{array}$ \\
\hline $\begin{array}{l}\text { EVA-3S, SPACE, } \\
\text { BACASS, ICSS, } \\
\text { CREST trials }\end{array}$ & $1466 / 3395$ & CEA/CAS & Multiple thresholds & $\begin{array}{l}\text { 30-day risk of death or any stroke } \\
\text { (combined) }\end{array}$ \\
\hline
\end{tabular}

BACASS, Basel Carotid Artery Stenting Study; BMT, best medical therapy; CAS, carotid artery stenting; CAVATAS, Carotid And Vertebral Artery Transluminal Angioplasty Study; CEA, carotid endarterectomy; CREST, Carotid Revascularisation Endarterectomy Versus Stenting Trial; ECST, European Carotid Surgery Trial; EVA-3S, Endarterectomy Versus Angioplasty in Patients with Symptomatic Severe Carotid Stenosis; ICSS, International Carotid Stenting Study; NASCET, North American Symptomatic Carotid Endarterectomy Trial; SPACE, Stent-Supported Percutaneous Angioplasty of the Carotid Artery Versus Endarterectomy.

of symptomatic carotid stenosis (surgical intervention (CEA, CAS) and/or BMT). Symptomatic stenosis was defined as carotid narrowing greater than $50 \%$ (or equivalent measurement) associated with an ipsilateral transient ischemic attack (TIA), amaurosis fugax or stroke.
We relied on individual trial reporting of carotid stenosis and outcomes, or summary analysis reported by systematic reviews. Four databases were searched: Ovid Medline, Embase, PubMed and the Cochrane Library on Wiley from 1991 to 2018 , as per our protocol ${ }^{7}$ with an updated 
search of Ovid Medline from 2018 to 2020 (search terms are listed in online supplemental table I). We collected publication information, study population information, severity of ipsilateral carotid stenosis, type of ipsilateral event, treatment allocation, follow-up time and outcome data. These results were described qualitatively. As per scoping review guidelines, a formal assessment of methodological quality was not performed. ${ }^{8}$

\section{RESULTS}

We identified 13 studies reporting sex-specific outcomes (table 1 and online supplemental figure 1 and table II) representing eight RCTs, three individual patient-data meta-analyses and 3184 female patients. ${ }^{34}{ }^{9-18}$ Inclusion criteria were largely consistent across studies with the majority recruiting symptomatic patients (TIA, nondisabling ipsilateral stroke or retinal infarction), with carotid stenosis $>50 \%$ based on either North American Symptomatic Carotid Endarterectomy Trial (NASCET) Collaborators or European Carotid Surgery Trialists' (ESCT) Collaborative Group criteria. Asymptomatic patients were also recruited in Carotid Revascularisation Endarterectomy Versus Stenting Trial (CREST). ${ }^{3}$ Baseline patient characteristics by sex were reported in two sub-analyses of the NASCET and CREST (online supplemental table III). ${ }^{312}$ Individual patient data meta-analyses that compared CEA to BMT ${ }^{4}$ or CEA to $\mathrm{CAS}^{910}$ did not evaluate sex-specific baseline characteristics.

Commonly reported outcomes included stroke (any or ipsilateral), death (any cause) or a combination thereof. The timepoints at which these outcomes were evaluated varied widely from trial to trial. Individual trials reported a range of follow-up times for long-term outcomes (2-10 years), often combining these measures with periprocedural events (30-day events; figure 1). A Cochrane analysis comparing CEA to CAS was able to assess 30-day periprocedural risk of death and stroke by acquiring individual patient data from five trials. ${ }^{10}$ Sex-specific assessments of long-term outcomes were largely limited to 5-year risk of stroke (ipsilateral or any) \pm death. ${ }^{459}$ Sex-specific differences relating to the degree of stenosis were only reported in studies comparing CEA to BMT. ${ }^{45}$

Overall, the individual patient data meta-analysis of NASCET and ESCT reported a lower absolute risk (ARR) for 5-year stroke and periprocedural death with CEA in women compared with men $(2.8 \%(2.2-7.8)$ vs $11.0 \%$ $(7.6-14.4)) .{ }^{5}$ When stratified by per cent stenosis, women with $\geq 70 \%$ benefited from the procedure (ARR: $9.9 \%$ ), while those with 50\%-69\% stenosis did not. A similar pattern was observed with time to procedure: only women who had a CEA performed within 2 weeks of the index event had a significant reduction in recurrent stroke. ${ }^{4}$ Comparing CEA to CAS at 30 days, there was a nonsignificant trend towards an increased hazard with CAS. ${ }^{10}$ No study compared CAS to BMT. Adverse events were not reported by sex.

\section{DISCUSSION}

We sought to perform a scoping review of the literature to determine the type and amount of information available relating to different management strategies for female patients with symptomatic carotid stenosis. Individual patient data analyses from high quality trials have reported on female outcomes for only select comparisons (CEA to BMT and CEA to CAS) in relation to specific outcome measures, (eg, 30-day outcome and 5-year ipsilateral stroke). No conclusions can be drawn about CAS versus CEA, or in relation to per cent stenosis or time to treatment. However, our appraisal of data available within individual trials indicates that a detailed, aggregated

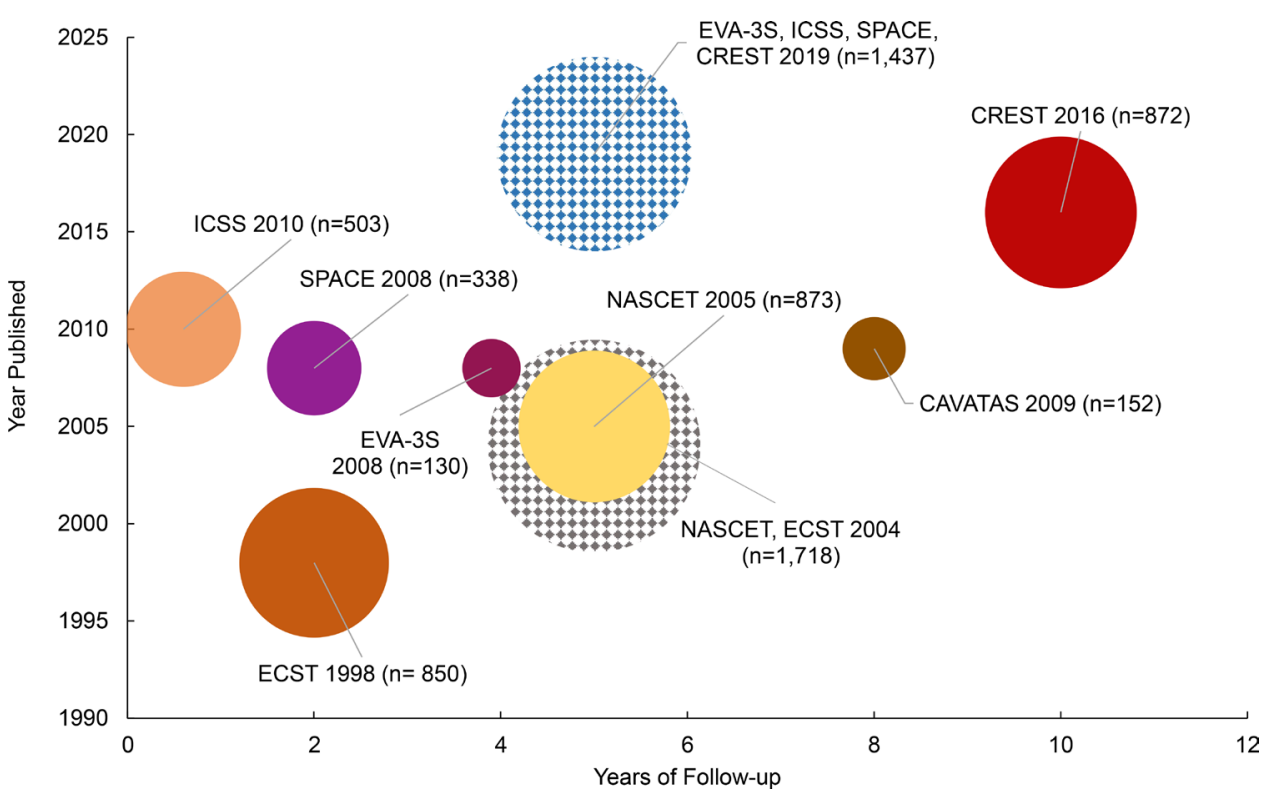

Figure 1 Sex-specific long-term outcomes. n represents the number of female patients. Pattern areas represent pooled individual patient data analysis. 
subgroup analysis in female compared to male patients is possible (table 1 and online supplemental table II). We contend that such an analysis would be necessary before female-only RCTs of carotid revascularisation are considered. A trial that would randomise female patients with symptomatic carotid stenosis away from standard revascularisation would need a strong scientific argument to be ethically justified, ${ }^{19}$ and we believe our scoping review demonstrates that more work is needed to draw any conclusions from the available scientific evidence.

\section{Author affiliations}

${ }^{1}$ Department of Medicine, Division of Neurology and Ottawa Hospital Research Institute, University of Ottawa, Ottawa, Ontario, Canada

${ }^{2}$ Epidemiology Program, Ottawa Hospital Research Institute, Ottawa, Ontario, Canada

${ }^{3}$ Stroke Prevention Clinic, Ottawa Hospital, Ottawa, Ontario, Canada

${ }^{4}$ Bioethics Program, UC Davis Department of Medicine, Sacramento, California, USA ${ }^{5}$ Universite Paris Descartes Faculte de Medecine Site Cochin, Paris, Île-de-France, France

${ }^{6}$ Service de Neurologie, Hôpital Sainte-Anne, Paris, France

${ }^{7}$ The University of Alabama at Birmingham School of Medicine, Birmingham, Alabama, USA

${ }^{8}$ School of Public Health, University of Alabama at Birmingham, Birmingham, Alabama, USA

Contributors Study was designed and conceptualised by VY, MS and OB. Search and screening was performed by $\mathrm{BD}, \mathrm{CH}$ and $\mathrm{OB}$. Manuscript was drafted by VY. Critical manuscript revision was performed by DD, SG, MF, PR and VH for intellectual content.

Funding This work is funded by grants from the Heart and Stroke Foundation of Canada (Seed Catalyst Grant for Women's Health; no award/grant number) and the Department of Medicine, University of Ottawa.

Competing interests None declared.

Patient consent for publication Not required.

Provenance and peer review Not commissioned; externally peer reviewed.

Open access This is an open access article distributed in accordance with the Creative Commons Attribution Non Commercial (CC BY-NC 4.0) license, which permits others to distribute, remix, adapt, build upon this work non-commercially, and license their derivative works on different terms, provided the original work is properly cited, appropriate credit is given, any changes made indicated, and the use is non-commercial. See: http://creativecommons.org/licenses/by-nc/4.0/.

\section{ORCID iDs}

Vignan Yogendrakumar http://orcid.org/0000-0001-8814-6853

Mark Fedyk http://orcid.org/0000-0002-0815-662X

\section{REFERENCES}

1 Brown MM, Raine R. Should sex influence the choice between carotid stenting and carotid endarterectomy? Lancet Neurol 2011;10:494-7.
2 Marulanda-Londoño E, Chaturvedi S. Carotid stenosis in women: time for a reappraisal. Stroke Vasc Neurol 2016;1:192-6.

3 Howard VJ, Lutsep HL, Mackey A, et al. Influence of sex on outcomes of stenting versus endarterectomy: a subgroup analysis of the carotid revascularization endarterectomy versus stenting trial (crest). Lancet Neurol 2011;10:530-7.

4 Rothwell PM, Eliasziw M, Gutnikov SA, et al. Sex difference in the effect of time from symptoms to surgery on benefit from carotid endarterectomy for transient ischemic attack and nondisabling stroke. Stroke 2004;35:2855-61.

5 Rothwell PM, Eliasziw M, Gutnikov SA, et al. Endarterectomy for symptomatic carotid stenosis in relation to clinical subgroups and timing of surgery. Lancet 2004;363:915-24.

6 Rothwell PM. Treating individuals 2. subgroup analysis in randomised controlled trials: importance, indications, and interpretation. Lancet 2005;365:176-86.

7 Bereznyakova O, Dewar B, Dowlatshahi D, et al. Benefit of carotid revascularisation for women with symptomatic carotid stenosis: protocol for a systematic review. BMJ Open 2019;9:e032140.

8 Tricco AC, Lillie E, Zarin W, et al. PRISMA extension for scoping reviews (PRISMA-ScR): checklist and explanation. Ann Intern Med 2018;169:467-73.

9 Brott TG, Calvet D, Howard G, et al. Long-Term outcomes of stenting and endarterectomy for symptomatic carotid stenosis: a preplanned pooled analysis of individual patient data. Lancet Neurol 2019;18:348-56.

10 Müller MD, Lyrer P, Brown MM, et al. Carotid artery stenting versus endarterectomy for treatment of carotid artery stenosis. Cochrane Database Syst Rev 2020;2:CD000515.

11 European Carotid Surgery Trialists' Collaborative Group. Randomised trial of endarterectomy for recently symptomatic carotid stenosis: final results of the MRC European carotid surgery trial (ECST). Lancet 1998:351:1379-87.

12 Alamowitch S, Eliasziw M, Barnett HJM, et al. The risk and benefit of endarterectomy in women with symptomatic internal carotid artery disease. Stroke 2005;36:27-31.

13 Ringleb PA, Allenberg J, et al, SPACE Collaborative Group. 30 day results from the space trial of stent-protected angioplasty versus carotid endarterectomy in symptomatic patients: a randomised noninferiority trial. Lancet 2006;368:1239-47.

14 Eckstein H-H, Ringleb P, Allenberg J-R, et al. Results of the StentProtected angioplasty versus carotid endarterectomy (space) study to treat symptomatic stenoses at 2 years: a multinational, prospective, randomised trial. Lancet Neurol 2008;7:893-902.

15 Mas J-L, Trinquart L, Leys D, et al. Endarterectomy versus angioplasty in patients with symptomatic severe carotid stenosis (EVA-3S) trial: results up to 4 years from a randomised, multicentre trial. Lancet Neurol 2008;7:885-92.

16 Ederle J, Bonati LH, Dobson J, et al. Endovascular treatment with angioplasty or stenting versus endarterectomy in patients with carotid artery stenosis in the carotid and vertebral artery transluminal angioplasty study (CAVATAS): long-term follow-up of a randomised trial. Lancet Neurol 2009;8:898-907.

17 Ederle J, Dobson J, et al, International Carotid Stenting Study investigators. Carotid artery stenting compared with endarterectomy in patients with symptomatic carotid stenosis (International carotid stenting study): an interim analysis of a randomised controlled trial. Lancet 2010;375:985-97.

18 Brott TG, Howard G, Roubin GS, et al. Long-Term results of stenting versus endarterectomy for carotid-artery stenosis. N Engl J Med 2016;374:1021-31

19 Shamy M, Fedyk M. Why the ethical justification of randomized clinical trials is a scientific question. $J$ Clin Epidemiol 2018;97:126-32. 